\section{Research directors form lobby}

SOME 280 French directors of research and the number is increasing daily - are making a public appeal to the government over what they consider to be swingeing cuts applied to science by the new Prime Minister, Jacques Chirac.

Last week, this new and spontaneous French pressure group published a halfpage advertisement in Le Monde, the country's major daily newspaper, paid for

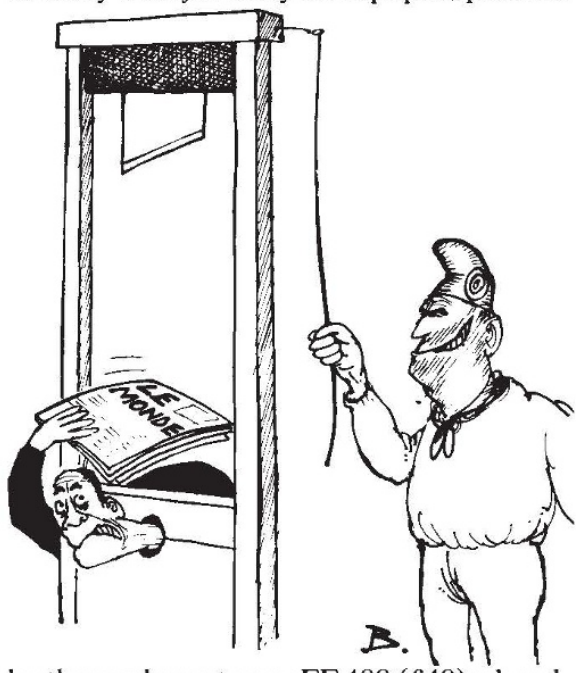

by themselves at over FF $400(£ 40)$ a head, lambasting the government for applying over half the recent cuts in total government spending to one ministry, that for research. A further advertisement is planned in Le Figaro, an important right-wing paper read by many of Chirac's supporters, if further funds can be raised.

The petition's organizers, Paris astrophysicists Jean Audouze and Pierre Encrenaz, said last week that the response of the country's leading scientists to their hastily-organized appeal had been "very encouraging". Some 50-60 per cent of those polled had responded within a week with sums from FF 100 to FF 1,000 to support the campaign.

"It really means that the directors have been shocked by this government's actions", said Encrenaz. In terms of cuts in "autorizations de programme", a strong indicator for future budgets as it represents sums which may be planned to be spent next year and beyond rather than actual cuts in current spending, 54 per cent of the government's recent savings fell on research and development, even though that represents only 2.3 per cent of the country's gross national product. This was enough to stir researchers into action. But worse may be to come.

Chirac has now told ministers that he will quadruple the present cuts, when the 1987 budget is announced in September. It is not clear whether research will suffer further, but Chirac did say in a letter to his ministers last week that the "overriding

necessity" to make major savings in government spending meant that "it will be impossible to satisfy the many sectional interests, however legitimate their arguments, that will certainly protest".

It is difficult to see this statement as anything but a mandate to the already powerful ministry of finance and budget to ignore all pleas, including those made in the form of advertisements in Le Monde. However, French scientists continue to hope for a softening of the government's line, even though Chirac's frosty embrace will include, he says, a cut of 1.5 per cent in all civil service positions (except education). This will strike a blow at scientists just like those who, unaware of the new policy, signed the new petition: researchers from the "grandes organismes" research councils, the Centre National de la Recherche Scientifique (CNRS), the Institut National de la Santé et de la Recherche Médicale (INSERM), and the Institut National de la Recherche Agronomique (INRA) who recently became civil servants after a great political battle.

Some scientists, indeed, see this winning of civil servant status as the prime cause of their present trouble, for some of

\section{SDI}

\section{Washington}

To students at the California Institute of Technology, satire has seemed the best way to express opposition to the Strategic Defense Initiative (SDI). Last month they held a competition for the most "destabilizing, unworkable or incredibly expensive" proposal to achieve SDI's goals.

The winner is planetary science graduate Greg Ojakangas. His proposal, estimated to cost $\$ 457$ million, involves developing a genetically engineered strain of pygmy hippopotamus. Hippos would be fed on a diet enriched with suitable radioactive materials and kept in cages with cathodes embedded in the walls. A continuous flow of electrons neutralizes the alpha particles emitted by the hippos' radioactive diet, forming helium and making the hippos lighter than air.

In the event of missile attack, an "optically thick cascade of buoyant hippos" rises to form a shield. Upon reaching the "hippopause", the height at which the mean hippo density (MHD) equals the atmospheric density, the hippos would fan out, forming a protective ROOPH (Readily Operative Overhead Protection by Hippos). In his proposal, Ojakangas reckons the hippos will remain buoyant for two days. After that, they will float gently to earth where they can be collected.

\title{
Abounding hypotheses floated
}

the principal and hardest opponents of the deal were the senior officials of the ministry of finance. Only an intervention by the now virtually powerless President François Mitterrand secured researchers their cherished "security". Now the enlarged finance ministry is wreaking its revenge, the story goes.

Whether or not this particular story is merely paranoia among the scientists, there is certainly considerable evidence that research is now being singled out for harsh treatment in France, after a few years of exactly the reverse. Only university researchers outside the research council system seem to have been relatively protected in posts (as teachers) and budget; but this research sector, by common consent, represents the weakest part of French science. Even Chirac's most extreme scientific advisers before his election last March argued that the universities had to be reformed and strengthened before the research council system was attacked (their criticism was that the latter was too centralist); but even their caveats now seem to be being bypassed.

"There seems to have been very little thought behind these new policies - they are very hasty policies", says Audouze. "We hope our campaign will convince ministers that these decisions are jeopardizing French research." Robert Walgate
Second prize went to physics graduate student David Palmer, whose proposal calls for splitting the Earth into hemispheres at the Equator. A large bearing allows the two hemispheres to be rotated. When radar detects a flight of missiles heading over the pole, large motors rotate the two hemispheres 180 degrees in opposite directions.

After this manoeuvre, the eastern and western hemispheres have changed places, and the missiles will land on the country from which they were originally launched.

Other less serious scenarios suggested putting everyone in the United States aboard dirigibles (since "no dirigible has been shot down in 20 years"); erecting a cardboard shield as the final layer of a multilayer defence (cardboard is lighter than plexiglass); and using a series of lenses to focus the ability of the Bermuda Triangle to make things disappear.

The Caltech competition was inspired by a similar effort at Cornell University last fall. The winning entry at Cornell proposed using a particle beam of tachyons, the particles arising in certain superstring theories which travel backwards in time. This would provide a pre-launch destruction capability even after an attack had been initiated. 